\title{
The Effectiveness of Using Recount Text to Improve Writing Skill For Grade III Students of Kalam Kudus Elementary School 2 Pematangsiantar
}

\author{
Natanael Saragih ${ }^{1}$, Roswita Silalahi ${ }^{2}$, Hilman Pardede ${ }^{3}$ \\ (Postgraduate Program of Universitas HKBP Nommensen, Pematangsiantar, Indonesia) \\ (Fakultas Ilmu Budaya, Universitas Sumatera Utara) \\ (Postgraduate Program of Universitas HKBP Nommensen, Pematangsiantar, Indonesia)
}

\begin{abstract}
This research focuses on the effect of recount genre to improve writing skill.The methotology which is used by using action research.The subjects are the Grade III Students of Kalam Kudus Elementary School 2 Pematangsiantar.Two classes, Galatia and Hosea were taken the subject of observation. This research object is to find the effect and extent of recount genre to improve students' ability in writing skill where the population and sample is taken from grade III students of Kalam Kudus Elementary School 2 Pematangsiantar.After the data been collected, the researcher finds out that the students in the grade III has improve in their writing. It has been also caused by the frequency of writing practise of recount genre, that recount genre can be applied to improve the writing skill of the students.
\end{abstract}

Key words : The effectiveness of using Recount text, writing skill, teaching writing, students'ability

\section{Introduction}

English is one of the international languages. It has very important role as a communication means for both oral and written. Therefore, English is taught to the young learners (children) in the early age in Indonesia and in almost all over the world. In Indonesia, English has been taught to young learners at pre-school until university. Many non-degree English courses are also offered outside the formal programs.

As we know in learning English there are four skills, which are very important for English learners. They are: Speaking skill, Writing skill, Reading skill and Listening skill. The four skills are very important, because they are basic of English learning. It is important to the students to master English orally and in writing, in order to be able to communicate and socialize with the community. Most of the students consider English as a difficult subject to learn. Many of them are failed to get a good mark and to fulfill the requirement in the passing grade score.

The third is the students commonly have difficulties and get bored in writing activity as they must spend many times to express their ideas into writing product. According to the researcher's experience during the teaching training, there are several problems done by the students in writing activities. The first problem is the students writing are not comprehensible, because the content of the composition is not relevant to the topic, the ideas are not clearly stated, the ideas and sentences are not well organized. The second problem is that there are many errors in vocabulary, grammar, and spelling. Another problem is the students have low motivation and are not interested in doing the task since the writing activities are not interesting. Usually, the students are asked to write sentences and paragraphs without being given some clue so that it is difficult for them to express their ideas on a piece of paper.

According to Rivers (1971:5), writng activities in foreign languages classes have taken from of the writing out paragdigm and grammatical exercises, dictations, tramslation from language to native language and initiative language and free composition.

There are various ways to organize the sentences in a piece of writing. One of them is recount text. Usually, the students have difficulty at telling their experience. This is because writing is difficult for them because they lack vocabulary, spelling, and grammar. The same condition is also found in Kalam Kudus Elementary School 2 Pematangsiantar.

In reference to the explanations above and the strong desire of finding the solution of these problems, the researcher has motivation to do the research which is to know the improvement of students' writing skill. It is hoped that the using of recount genre can improve the students' writing skill. 
From the statement above, the researcher hopes the students can be motivated in learning English. Therefore, the research question raised by the researcher is: "How Effective is the use of Recount Text to improve writing skill for grade III students in Kalam Kudus Elementary School 2 Pematangsiantar?"

\subsection{Writing}

\section{Literature Review}

Writing is one of the language skills which is important in our life. Through writing, we can inform others, carry out transaction, persuade, infuriate, and tell what we feel. However, we know that writing or learning to write especially in a second language is not simply a matter of "writing things done". It is one of the four basic skills (listening, reading, speaking, writing) that are very complex and difficult to learn. There are some characteristics of a good writing. A text or paragraph may these for to be understood as a visible division of the subject method. According to Boardman (2008:18-25) There are three characteristics in writing a good text or paragraph, namely:

\section{Coherence}

A paragraph has coherence when the supporting sentences are ordered according to a principle. The sentences are put in order so that the reader can understand your ideas easily. The principles for ordering depend on the types of paragraph you are writing. Coherence means stick together, coherence is basically a matter of having the part of a piece of writing in the right with the clear process.

\section{Cohesion}

Another characteristic of a good paragraph is Cohesion. When a paragraph has cohesion, all the supporting sentences connect to each other in their support of the topic sentence.

\section{Unity}

The final characteristic of a well-written paragraph is unity. All the supporting sentences should relate to the topic sentence. Order in text or paragraph is like organization easy, but is smaller in space so it may be simpler to consider order as direction. Thus order chronological steps to express the idea the written form.

\subsection{Recount Text}

According to Knapp (2005: 224), Recount Text, basically it is written out to make a report about an experience of a series of related event. A recount is written out to inform an event or to entertain people. Recount Text is text function as for telling an incident in the past.

Recount is to tell "what happened". A recount text has a social function. The purpose of a social function is to retell an event with a purpose to inform or entertain the readers (Siahaan and Shinoda, 2008: 9). Recount tells a series of events and evaluate their significance in some way. It is also to give audience a descriptions of what occurred and when it occurred. The story recount has expressions of attitude and feeling, usually made by narrator about the events.

\subsection{Constructing in Written Recount Text}

Boardman (2008:287) stated that the steps for constructing of written recount text are:

a. The First paragraph that give background information about who, what, where and when. It is called on orientation.

b. A record of events usually recounted in chronological order, named; event 1 , event 2 , event 3 .

c. A personal comment and or evaluative remarks, which are interspersed throughout the record of events named evaluation.

d. A reorientation which "rounds off "the sequences of events or retell about what happened in the end.

Boardman (2008:287) the language features usually found in a recount:

a. Use of nouns and pronouns to identify people, animals or things involved.

b. Use of past action verbs to refer the events.

c. Use of past tense to located events in relation to speaker`s or researcher`s time.

d. Use conjunctions and time connectives to sequence the event.

e. Use of adverb and adverbial phrases to indicate place and time.

f. Use of adjectives to describe nouns.

According Boardman (2008:287) in making of functional grammar, the significant common grammatical patterns of recount include:

a. Focus on specific participant.

b. Use of material process or action verb. 
c. Circumstance of time and place.

d. Use past tense and focus on temporal sequences.

Below is an example of recount text adapted from: English in Focus for Basic School Grade III

\section{My Basketball Experience}

Orientation Event 1

Event 2

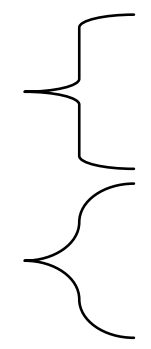

When I was in Junior High School, I really loved basketball.

Every Saturday afternoon I practiced in school field with my team and my coach. They were strong and smart players. My coach, Mr. Sentana was a kind person. But, while he was coaching us, he was very discipline. He would grounded anyone who came late and not obeyed the team's rules.

With Mr.Sentana, our team won many tournaments in many big cities. Our team named after school, 67 Team ( from SMP 67) and we had so many fans too. Now, I still love basketball and have a team too.

Re-Orientation But, my parents warn me to play attention more to study, basketball just for hobby

2.4 The Effectiveness of Using Recount Genre for Grade III Students Kalam Kudus Elementary School

As mentioned before that recount genre has certain generic structure which includes three parts: orientation, events, and re-orientation. Moreover, to know whether the recount genre which was made is effective or not, the teacher could measure it from some criteria, such as:

1. There are three parts of generic structure in the text that are orientation, events, and re-orientation.

2. The use of simple sentences including Subject $(\mathrm{S})$, Predicate $(\mathrm{P})$, and Object $(\mathrm{O})$. It was also used to avoid the ambiguous sentences in the students' writing.

If those criteria can be reached, it will make the students' writing are effective enough to express their idea, at least it had fulfilled the criteria as short simple recount genre.

\section{Research Methodology}

This chapter talks about the method and the procedure to answer the problem of this research. Methodology is a specific set of procedure of researching. It explains the design, population, sample, and technique for collecting data and data analysis.

\section{Data Analysis}

After the data were collected, the data were analyzed through the pre-test up to post- test. The researcher usef quantitative analysis to analyze the test. The research was done by combining two classes to be one in two cycles. The sum of the students from two classes are 39 students.

\subsection{Data Analysis of Cycle II}

\subsubsection{Planning}

The researcher made the research instrument which were needed in this planning phase, such as lesson plan, which contained about teaching material, teaching procedure, and some exercise. In this case, the researcher made lesson plan and ask the students to write their own experiences in a piece of paper. The researcher will see the improvement of the students in writing skill from the score of pre-test to post test.

\subsubsection{Acting}

In the first meeting, the researcher gave a pre test to students to write their yesterday activities from morning up to night and from the test, it is found that the students' score was low. It was followed by 39 students. After doing the pre test, the researcher explained to the students about recount genre. The researcher explained thet recount genre is a kind of genre which tell about what we feel, our idea or tell about our experience. The researcher also explained about past tense that using in recount genre.

\subsubsection{Observing}

The researcher had explained about recount genre to the students. However, when the researcher prepared the students to follow the learning process is less good. Related with the students' activities there were some students who did not pay attention to the researcher explanation. At the end of the lesson, the researcher gave the post test to the students. the purpose of this activity is to check the students' understanding about the lesson. 
The researcher checked the students' answer sheet of the post test. It was found that some of the students were good in writing recount genre but some were not. The students' score increased from the pre test to post test however a few of them did not. The researcher tried to solve the problem in the second Cycle.

\subsubsection{Reflecting}

Actually, in this reflecting phase, the researcher had reflected about the difficulties of the students in writing recount genre. In this case, the researcher saw that some students difficult to use past tense in writing recount genre. Consequently, the researcher makes the students be more practicing in memorizing the second verb that used in past tense.

Therefore based on the reflecting above, this cycle must be contained in the next cycle, in order to improve student's writing skill by using recount genre.

\subsubsection{Students'Score of Cycle I}

The data gained from the students' score after applying the pre test and post test in Cycle I. The result of the students' score could be seen in the following table. The students' score got improvement in every test. The improvement of the students' score by using recount genre can be seen in Table 1 .

Table 1. The Result of The Students' Score For Cycle I

\begin{tabular}{|c|c|c|}
\hline \multirow{2}{*}{$\begin{array}{l}\text { Student } \\
\text { Identity }\end{array}$} & \multicolumn{2}{|c|}{ Ccyle I } \\
\hline & Pre Test & Post Test \\
\hline 1 & 25 & 35 \\
\hline 2 & 45 & 80 \\
\hline 3 & 42 & 52 \\
\hline 4 & 0 & 25 \\
\hline 5 & 45 & 50 \\
\hline 6 & 55 & 85 \\
\hline 7 & 30 & 55 \\
\hline 8 & 40 & 70 \\
\hline 9 & 30 & 60 \\
\hline 10 & 40 & 55 \\
\hline 11 & 0 & 45 \\
\hline 12 & 0 & 50 \\
\hline 13 & 40 & 50 \\
\hline 14 & 50 & 70 \\
\hline 15 & 50 & 75 \\
\hline 16 & 42 & 82 \\
\hline 17 & 45 & 70 \\
\hline 18 & 30 & 70 \\
\hline 19 & 45 & 65 \\
\hline 20 & 35 & 78 \\
\hline 21 & 30 & 80 \\
\hline 22 & 25 & 50 \\
\hline 23 & 35 & 60 \\
\hline 24 & 35 & 50 \\
\hline 25 & 45 & 60 \\
\hline 26 & 40 & 65 \\
\hline 27 & 45 & 70 \\
\hline 28 & 55 & 60 \\
\hline 29 & 50 & 70 \\
\hline 30 & 50 & 55 \\
\hline 31 & 55 & 65 \\
\hline 32 & 50 & 60 \\
\hline 33 & 40 & 60 \\
\hline 34 & 40 & 55 \\
\hline 35 & 50 & 65 \\
\hline 36 & 60 & 85 \\
\hline 37 & 45 & 65 \\
\hline 38 & 50 & 60 \\
\hline 39 & 55 & 65 \\
\hline TOTAL & 1544 & 2422 \\
\hline MEAN & 39.58 & 62.10 \\
\hline
\end{tabular}

Based on the data above, after the data analyzed, it shows that the mean in pre test is 39.58 and the highest score is 60 and the lowest score is 0 . The data above shows that the mean in post test is 62.10 and the highest score is 85 and the lowest score is 25 . 


\subsection{Data Analysis of Cycle II}

\subsubsection{Planning}

The researcher modified the prevoius lesson plan into new lesson plan which had related by using recount genre to improve students' writing skill. In this planning phase, there were some modification which are the different material and exercises. The researcher give more examples of recount genre to the students. It was done to make students give more attention to the researcher's explanation and to avoid the students were noisy in the class.

\subsubsection{Acting}

In the second meeting, the researcher gave a pre test to the students to review the previous lesson in order to refresh their mind. The topic is about to write their own experience. It was followed by 39 of Grade III Students in Kalam Kudus Elementary School 2 Pematangsiantar.

Some of the students were very enthusiastically raising their hands when the teacher asked about the second verb that used in past tense.

\subsubsection{Observing}

In this observing phase of the second cycle, the researcher performance was better than the previous cycle. The students more active and enthusiastic in teaching and learning process than in the first cycle. It could be seen from their interaction in the classroom.

At the end of the lesson, the researcher gave the post test to the students. this activities had purpose to check the students' understanding about the lesson. The researcher asked the students to write their own experience. Having checked the students' paper, the researcher found that the students' score show the improvement. The second cycle test show that there was good improvement of the students in writing skill by using recount genre.

\subsubsection{Reflecting}

After analyzing the data of this second cycle, there was improvement in the students' score from pre test to post test. In addition, they interested and enjoyed with the use of recount genre in teaching writing during the teaching and learning process.

\subsubsection{Students' Score of Cycle II}

The students' score got improvement in every test. The improvement of the students' score by using recount genre to improve writing skill can be seen in Table 2 .

Table 2. The result of the Students' Score for Cycle II

\begin{tabular}{|c|c|c|}
\hline \multirow{2}{*}{$\begin{array}{l}\text { Student } \\
\text { Identity }\end{array}$} & \multicolumn{2}{|c|}{ Ccyle II } \\
\hline & Pre Test & Post Test \\
\hline 1 & 50 & 75 \\
\hline 2 & 65 & 80 \\
\hline 3 & 45 & 60 \\
\hline 4 & 55 & 70 \\
\hline 5 & 60 & 75 \\
\hline 6 & 65 & 85 \\
\hline 7 & 55 & 70 \\
\hline 8 & 50 & 75 \\
\hline 9 & 55 & 65 \\
\hline 10 & 70 & 80 \\
\hline 11 & 55 & 70 \\
\hline 12 & 50 & 75 \\
\hline 13 & 55 & 75 \\
\hline 14 & 60 & 80 \\
\hline 15 & 50 & 75 \\
\hline 16 & 60 & 85 \\
\hline 17 & 55 & 75 \\
\hline 18 & 60 & 75 \\
\hline 19 & 75 & 85 \\
\hline 20 & 60 & 80 \\
\hline 21 & 70 & 85 \\
\hline 22 & 60 & 75 \\
\hline 23 & 70 & 80 \\
\hline 24 & 65 & 80 \\
\hline 25 & 60 & 75 \\
\hline 26 & 65 & 80 \\
\hline 27 & 75 & 90 \\
\hline
\end{tabular}




\begin{tabular}{|c|c|c|}
\hline \multirow{2}{*}{$\begin{array}{c}\text { Student } \\
\text { Identity }\end{array}$} & \multicolumn{2}{|c|}{ Ccyle II } \\
\cline { 2 - 3 } & Pre Test & Post Test \\
\hline 28 & 70 & 80 \\
\hline 29 & 75 & 85 \\
\hline 30 & 65 & 80 \\
\hline 31 & 55 & 70 \\
\hline 32 & 65 & 75 \\
\hline 33 & 60 & 70 \\
\hline 34 & 65 & 80 \\
\hline 35 & 65 & 75 \\
\hline 36 & 75 & 90 \\
\hline 37 & 65 & 70 \\
\hline 38 & 55 & 75 \\
\hline 39 & 65 & 80 \\
\hline TOTAL & $\mathbf{2 3 9 5}$ & $\mathbf{3 0 0 5}$ \\
\hline MEAN & $\mathbf{6 1 . 4 1}$ & $\mathbf{7 7 . 0 5}$ \\
\hline
\end{tabular}

Based on the data above, after analyzing the data, it shows that the mean in pre test is 58.20 and the highest score is 75 and the lowest score is 45 . The mean in post test is 77.05 and the highest score is 90 and the lowest score is 60. The result from both groups can be seen bellow:

1. The Result of Pre-Test and Post Test of Cycle I

The total score of pre-test $\quad: 1544$

The mean of pre-test $: 39.58$

The highest score of pre-test $\quad: 60$

The lowest score of pre-test $\quad: 0$

The total score of post-test $: 2422$

The mean of post-test $: 62.10$

The highest score of post-test $\quad: 85$

The lowest score of post-test $\quad: 25$

2. The Result of Pre-Test and Post-Test of Cycle II

The total score of pre-test $\quad: 2395$

The mean of pre-test $\quad: 61.41$

The highest score of pre-test : :75

The lowest score of pre-test $\quad: 45$

The total score of post-test : :3005

The mean of post-test $\quad: 77.05$

The highest score of post-test : 90

The lowest score of post-test $\quad: 60$

4.3 The Validity of the test

The test was valid for the purpose of the test has sufficient evidence that correlate with ability to be tested. For the test, it is calculated by using the formula as follows:

Table 3. The Calculation of the Validity Test

\begin{tabular}{|c|l|l|l|l|l|}
\hline \multirow{2}{*}{$\begin{array}{c}\text { Student } \\
\text { Identity }\end{array}$} & $\mathbf{X}$ & $\mathbf{Y}$ & & $\mathbf{X}^{\mathbf{2}}$ & $\mathbf{Y}^{\mathbf{2}}$ \\
\hline & $\mathbf{X}$ & 75 & 2500 & $\mathbf{X Y}$ & \\
\hline 2 & 50 & 80 & 4225 & 6625 & 3750 \\
\hline 3 & 65 & 60 & 2025 & 3600 & 5200 \\
\hline 4 & 45 & 70 & 3025 & 4900 & 2700 \\
\hline 5 & 55 & 75 & 3600 & 5625 & 3850 \\
\hline 6 & 60 & 85 & 4225 & 7225 & 5500 \\
\hline 7 & 65 & 70 & 3025 & 4900 & 3850 \\
\hline 8 & 55 & 75 & 2500 & 5625 & 3750 \\
\hline 9 & 50 & 65 & 3025 & 4225 & 3575 \\
\hline 10 & 70 & 80 & 4900 & 6400 & 5600 \\
\hline 11 & 55 & 70 & 3025 & 4900 & 3850 \\
\hline 12 & 50 & 75 & 2500 & 5625 & 3750 \\
\hline 13 & 55 & 75 & 3025 & 5625 & 4125 \\
\hline 14 & 60 & 80 & 3600 & 6400 & 4800 \\
\hline 15 & 50 & 75 & 2500 & 5625 & 3750 \\
\hline
\end{tabular}




\begin{tabular}{|c|c|c|c|c|c|}
\hline \multirow{2}{*}{$\begin{array}{l}\text { Student } \\
\text { Identity }\end{array}$} & \multicolumn{2}{|c|}{ Cycle II } & \multirow[t]{2}{*}{$\mathbf{X}^{2}$} & \multirow[t]{2}{*}{$\mathbf{Y}^{2}$} & \multirow[t]{2}{*}{$\mathbf{X Y}$} \\
\hline & $\mathbf{X}$ & $\mathbf{Y}$ & & & \\
\hline 16 & 60 & 85 & 3600 & 7225 & 5100 \\
\hline 17 & 55 & 75 & 3025 & 5625 & 4125 \\
\hline 18 & 60 & 75 & 3600 & 5625 & 4500 \\
\hline 19 & 75 & 85 & 5625 & 7225 & 6375 \\
\hline 20 & 60 & 80 & 3600 & 6400 & 4800 \\
\hline 21 & 70 & 85 & 4900 & 7225 & 5950 \\
\hline 22 & 60 & 75 & 3600 & 5625 & 4500 \\
\hline 23 & 70 & 80 & 4900 & 6400 & 5600 \\
\hline 24 & 65 & 80 & 4225 & 6400 & 5200 \\
\hline 25 & 60 & 75 & 3600 & 5625 & 4500 \\
\hline 26 & 65 & 80 & 4225 & 6400 & 5200 \\
\hline 27 & 75 & 90 & 5625 & 8100 & 6750 \\
\hline 28 & 70 & 80 & 4900 & 6400 & 5600 \\
\hline 29 & 75 & 85 & 5625 & 7225 & 6375 \\
\hline 30 & 65 & 80 & 4225 & 6400 & 5200 \\
\hline 31 & 55 & 70 & 3025 & 4900 & 3850 \\
\hline 32 & 65 & 75 & 4225 & 5625 & 4875 \\
\hline 33 & 60 & 70 & 3600 & 4900 & 4200 \\
\hline 34 & 65 & 80 & 4225 & 6400 & 5200 \\
\hline 35 & 65 & 75 & 4225 & 5625 & 4875 \\
\hline 36 & 75 & 90 & 5625 & 8100 & 6750 \\
\hline 37 & 65 & 70 & 4225 & 4900 & 4550 \\
\hline 38 & 55 & 75 & 3025 & 5625 & 4125 \\
\hline 39 & 65 & 80 & 4225 & 6400 & 5200 \\
\hline TOTAL & $\Sigma X=2395$ & $\Sigma Y=3005$ & $\Sigma X^{2}=149375$ & $\Sigma Y^{2}=233075$ & $\begin{array}{l}\Sigma X Y= \\
185975\end{array}$ \\
\hline
\end{tabular}

It was calculated by using the formula:

$$
\begin{aligned}
& r x y=\frac{39(185975)-(2395)(3005)}{\sqrt{\left\{39(149375)-(2395)^{2}\left\{39(233075)-(3005)^{2}\right\}\right.}} \\
& r x y=\frac{7253025-7196975}{\sqrt{[5825625-5736025\}\{9089925-9030025\}}} \\
& r x y=\frac{56050}{\sqrt{(89600)(59900)}} \\
& r x y=\frac{56050}{\sqrt{5367040000}} \\
& r x y=0.76
\end{aligned}
$$

4.2 The Reliability of the test

$$
\begin{aligned}
& r_{11}=\frac{2 \times r^{1 / 21 / 2}}{\left(1+r^{1 / 21 / 2}\right)} \\
& r_{11}=\frac{2 \times 0.76}{(1+0.76)} \\
& r_{11}=\frac{1.52}{1.76} \\
& r_{11}=0.86
\end{aligned}
$$

4.4 Testing the T-test Formula for Dependent Sample to Research Class

The T-test formula for dependent sample to research class is to find out the before and after attitude scores of 39 students in research classes and role play of the students that have improved the students' writing achievement. The data has been calculated by using T-test formula as follows: 
Table 4. Before and After Attitude Scores of 39 Students in Research Classes

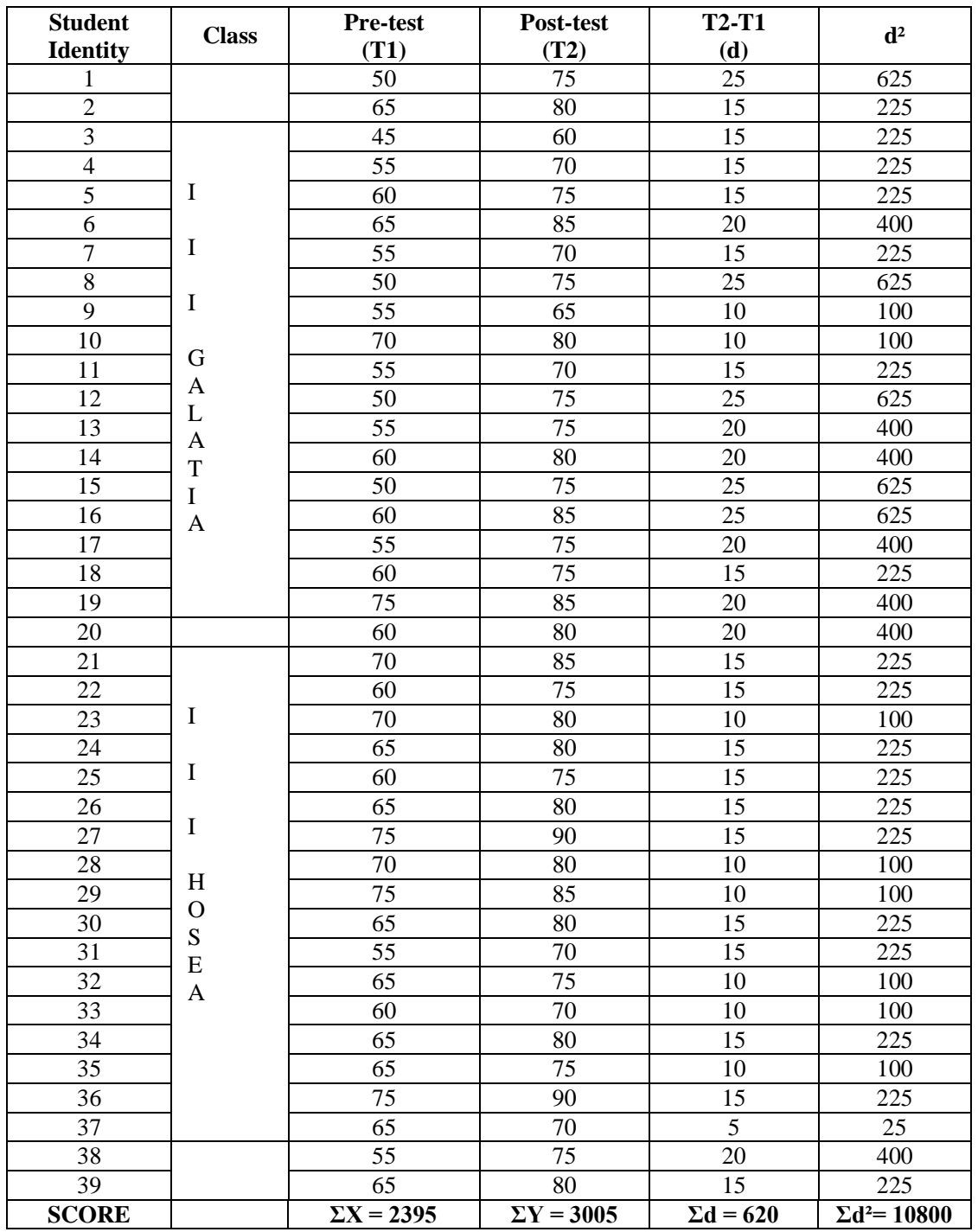

Based on the analysis, there are several discoveries which are actually found by the researcher. There are as the following:

1. Based on the finding, the alternative hyphotesis (H1) was accepted and null hypothesis (H0) was rejected. It shows by the improvement of students' score from the pre test to post test in cycle II.

2. The conclusion of their improvement can be seen in the Table 5:

Table 5. The result table cycle I and II by pre-test and post-test

\begin{tabular}{|c|c|c|}
\hline \multirow{2}{*}{ TEST } & \multicolumn{2}{|c|}{ CYCLE } \\
\cline { 2 - 3 } & I & II \\
\hline PRE TEST & 39.58 & 58.20 \\
\hline POST TEST & 62.10 & 61.41 \\
\hline
\end{tabular}

Based on the result, finally the researcher interpret that the answer to the problem of this thesis "What is the effectiveeness of using recount genre to improve writing skill in Kalam Kudus Elementary School 2 Pematangsiantar?

The answer is that by using recount genre it can help the students to improve their writing skill because in recount genre the students can share what the events or experiences that happen to them in a paper.

\section{Conclusion}

Having analyzed all the data, the researcher decribes the conclusion from the 2 (two) data that were written by the third year students in Kalam Kudus Elementary School 2 Pematangsiantar, they are : 
1. The students' writing skill incresed from the pre test to post test. It can seen from the mean of Post Test (62.10) was higher than the mean of Pre-Test (39.58) in Cycle I. The mean score of the Post Test (77.05) was higher that the mean of Pre Test (61.41) in Cycle II. It means that using recount genre has significant affect to the students' mastery in writing recount genre.

2. The English teaching and learning process Grade III students in Kalam Kudus Elementary School Pematangsiantar is very difficult because the students of the school are mostly passive. Besides, this institution has limited material resources. For the researcher, it is also the first experience for her to be English teacher there.

3. The researcher decide to use recount genre in delivering English skill, especially in writing. Recount genre can transfer the students' idea so that it makes the next more communicative than if the researcher uses other genre, such as report and narrative. The researcher uses guided writing in teaching writing in Kalam Kudus Elementary School 2 Pematangsiantar,. The researcher gives some exercise to them. Based on the result, most of their writing has improved. It has been also caused by the frequency of writing practise of recount genre. This is the fact, that recount genre can be applied to improve the writing skill of the students.

4. Some problems influence the process of teaching recount genre to Grade III Students Pematangsiantar. Those problems which come from the students are: the using of grammar and lack of vocabulary; the influence of Indonesian language; punctuation; laziness; acting as if tehy were elementary school students; unstable emotion and uninteresting. The mistakes of using tenses, pronoun, vocabulary, word order, preposition, spelling, capitalization and punctuation can be minimized by using simple sentences in writing consists of $\mathrm{S}, \mathrm{V}$, and $\mathrm{O}$ to avoid ambiguous sentences.

\section{References}

[1] Temperly Rivers, A practical guide to the teaching of english as a second or foreign language (New York : Oxford University Press, 1971)

[2] A.Cynthia, Boardman, Writing to communicate (New York: Pearson Education, 2008).

[3] Peter Knaap, Genre, text, and grammar (Sydney: University of New South Wales, 2005).

[4] Oxford Dictionary, Oxford learners pocket dictionary (New York: University Press, 1995).

[5] Sanggam Siahaan and Kisno Shinoda, Generic text structure (Yogyakarta: Graha Ilmu, 2008). 